\title{
An ISM/UWB antenna with offset feeding and slotted ground plane for body-centric communications
}

\author{
Yi Ye Sun, Sing Wai Cheung, Tung Ip Yuk \\ Dept. of Electrical and Electronic Engineering, the University of Hong Kong, Hong Kong
}

Email address:

yysun@eee.hku.hk(Yi Ye Sun), swcheung@eee.hku.hk(Sing Wai Cheung), tiyuk@eee.hku.hk(Tung Ip Yuk)

\section{To cite this article:}

Yi Ye Sun, Sing Wai Cheung, Tung Ip Yuk. An ISM/UWB Antenna with Offset feeding and Slotted Ground Plane for Body-centric Communications. Journal Electrical and Electronic Engineering. Vol. 1, No. 2, 2013, pp. 45-50. doi: 10.11648/j.jeee.20130102.12

\begin{abstract}
An offset-fed ISM/Ultra-wideband (UWB) antenna with a slotted ground plane designed for on-body communications is presented in this paper. The antenna consists of a radiator very close to a square shape, a feed line slightly offset from the middle along the radiator side and three rectangular slots at the top edge of the ground plane. The offset feed line is used to improve the radiation pattern for on-body communications and the slots on the ground plane are used to improve impedance matching of the antenna. The antenna is studied using computer simulation. For verification of simulation results, the antenna is fabricated and measured. Simulated and measured results show good agreements in terms of reflection coefficient, gain, efficiency and radiation pattern. Measured results show that the antenna can achieve a wide bandwidth from 2.38 to $14.5 \mathrm{GHz}$ with more omnidirectional radiation patterns in the E-plane than conventional monopole, making it a potential candidate for on-body communications using UWB.
\end{abstract}

Keywords: ISM/UWB Antenna; Offset Feed, Body-Centric Communications

\section{Introduction}

Since the Federal Communications Commission (FCC) allocated 7.5 GHz spectrum from 3.1 to $10.6 \mathrm{GHz}$ for radio applications with low power emission in 2002 [1], Ultra-wideband (UWB) systems have received much attention. However, it needs to be reminded that lots of fundamental works had been done in the last century [2-5]. The design of efficient and compact size antennas for wideband applications is still a major challenge nowadays. Many microstrip-fed and coplanar waveguide-fed antennas have been reported for UWB applications [6-12] and the UWB propagation channel has also been studied [13]. These antennas employed either the monopole configuration with different shapes (circular ring, ellipse, annual ring, triangle, pentagon or hexagon) $[10,11]$ or the dipole configuration (e.g. bow-tie antennas) [9]. Since the Industrial, Scientific and Medical (ISM) band from 2.4-2.484 GHz covers the IEEE $802.1 \mathrm{~b} / \mathrm{g}$ standards which are very popular in many countries for accessing the internet, it is useful to have a single antenna to support both the UWB and ISM band.

Different techniques can be used to increase the impedance bandwidths of planar monopole antennas, e.g. using slots on the ground plane [11] and slot antenna geometry $[12,14]$, increasing the elliptical ratio of ellipse-shaped monopole [15], adding stairs to the lower edge of the radiator [16], adding a bent stub to one side of the radiating element and stepping the ground plane [17]. Many antennas for ISM and UWB applications have also been proposed. In [18], an $L$-shaped strip was added to one side of a semi-bevelled-rectangle patch radiator to cover both the ISM and UWB bands. In [19, 20], stub or a folded strip were added to the centre of the radiators to achieve the bandwidth requirement. Different specific applications have also been reported such as for wireless universal serial bus (WUSB) dongle applications in [21] or laptop applications in [22]. For body-centric wireless communications systems, with the existence of human body, several fundamental requirements, such as wide impedance bandwidth, low profile, high front-to-back ratio and good radiation characteristics in the proximity of the body, are needed to be fulfilled in the design of the antennas [23-27]. Depending on the channel used for propagation of the signals, body-centric wireless communication systems can be divided into in-body, on-body and off-body communications [23]. In-body communication refers to communication between two or more devices through the human body, which is from inside of the body to the outside of the body. For off-body communication, it is communication between devices on body with other devices away from the body. An 
antenna for off-body communication should have radiation patterns directed away from the body. For on-body communications, it refers to communication between two or more devices which are mounted on the same human body. Thus it is desirable for the antenna to have an omnidirectional radiation pattern on the body surface to achieve good on-body propagation. Most UWB antennas proposed for on-body communications have made different kinds of compromise. In [24], a UWB monopole antenna was installed perpendicularly to the body surface in order to have an omnidirectional radiation pattern in the E-plane on the body surface. However, the design had high profile. Some other designs of UWB monopole antennas were proposed to put in parallel with the body surface to achieve low profile [25-27]. However, the radiation pattern in the E-plane on the body surface then was not omnidirectional.

In this paper, an ISM/UWB monopole antenna employing a radiator very close to a square shape, a feed line slightly offset from the middle along the side of the radiator and a ground plane with three rectangular slots is proposed for on-body communications. To the best of our knowledge, this is the first ISM/UWB antenna designed for body-centric communications. The antenna is studied, designed and fabricated on a Rogers substrate. Results show that the antenna has a wide impedance bandwidth from 2.38 to $14.5 \mathrm{GHz}$ and a radiation pattern more omnidirectional in the E-plane than those of other monopole antennas, which makes it suitable for on-body communications.

The proposed antenna is a further study and an improvement of our previous design in [10]. In the previous design, the antenna on a FR4 substrate with a very small ground plane and could not cover the whole bandwidth of 3.1-10.6 GHz allocated by the US-FCC. Since FR4 substrate does not have constant electrical characteristics particularly at high frequencies, there were large discrepancies between the measured and simulated results in [10]. Moreover, the antenna employed six ground slots on the ground plane. Further studies on the operation of the antenna have shown that three slots are enough if placed in the correct positions. Thus in the present design, the antenna has only three slots on the ground plane and is designed on a Rogers RO4350 substrate.

\section{Antenna Design}

The geometry of the proposed ISM/UWB monopole antenna with microstrip-fed is shown in Fig. 1. The antenna has a radiator very close to a square shape with an area of $W_{P} \times L_{P}$. The microstrip-feed line has a width of $w_{f}$ to achieve $50-\Omega$ characteristics impedance and is placed slightly offset from the middle of the radiator edge. The radiator and feed line are printed on one side of the substrate, and the ground plane with a height of $h_{g}$ is printed on the other side. Three rectangular slots, slots 1,2 and 3 as shown in Fig. 1(a), each with a dimension of $w_{s} \times h_{s}$ are added to the top edge of the ground plane. The positions of these slots on the ground plane are quite critical on achieving a good matching per- formance. The antenna is studied, designed and optimized using the EM simulation tool, CST, on a substrate, Rogers RO4350, with a thickness of $0.8 \mathrm{~mm}$, a relative permittivity of 3.5 and a total area of $W \times L$. The optimized parameters are listed in Table 1 which is used to fabricate the antenna as shown in Fig. 1(c) for measurement using the antenna measurement equipment, Satimo Starlab.

Table 1. Optimized parameters of proposed antenna

\begin{tabular}{cccc}
\hline Parameter & Value & Parameter & Value \\
\hline$W$ & 40 & $h_{g}$ & 9.375 \\
$L$ & 33 & $l 1$ & 6.6 \\
$W_{p}$ & 22 & $l 2$ & 6.8 \\
$L_{p}$ & 21.75 & $l 3$ & 3.2 \\
$D$ & 10 & $l 4$ & 12.9 \\
$d$ & 4.3 & $w_{s}$ & 1.5 \\
$w_{f}$ & 1.7 & $h_{s}$ & 3.5 \\
$h_{f}$ & 10.875 & & \\
\hline
\end{tabular}

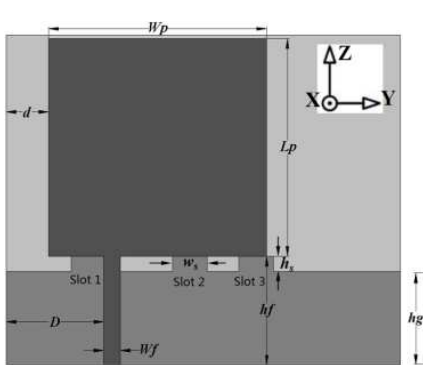

(a) Top view

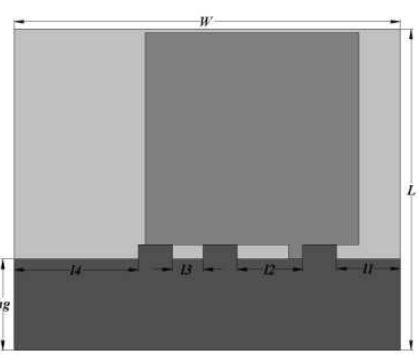

(b) Bottom view

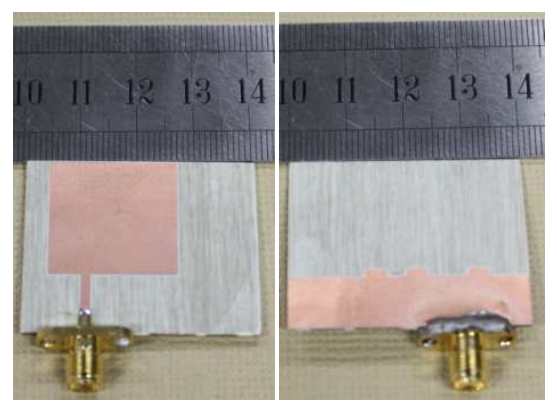

(c) Photos of the antenna

Figure 1. Geometry of proposed antenna

\section{Parameter Study}

\subsection{Simulated S11}

Results of computer simulation have shown that the number of slots used on the ground plane, the height of the slots $h_{s}$ and the positions of the slots all play important roles in impedance matching. With the optimum slot size of $w_{s} \times h_{s}=1.5 \times 3.5 \mathrm{~mm}^{2}$, the simulated $\mathrm{S} 11$ using only one slot and two slots with different positions are shown in Fig. 2 . Note that the positions of slots 1, 2 and 3 are determined by parameters $l 1, l 2$ and $l 3$. It can be seen in Fig. 2(a) that when only one slot is used, the bandwidth cannot cover the whole UWB. As $l 1$ increases from 6 to $21 \mathrm{~mm}$, i.e. slot 1 moves from left side of the ground plane under the radiator 
to right side, the impedance bandwidth of the antenna decreases. With $l 1=6$, the bandwidth is from 2.2 to $9.7 \mathrm{GHz}$, and with $l 1=21$, the bandwidth is only from 2.3 to 7.5 $\mathrm{GHz}$. With the use of two slots on the ground plane, the simulated S11 with $l 1$ is fixed at $6 \mathrm{~mm}$ is shown in Fig. 2(b). It can be seen that, with $l 2=12$, the antenna has wider bandwidths and achieve an impedance bandwidth from 2.2 to $11.8 \mathrm{GHz}$, covering both ISM and UWB band. In our design, a third slot is added to further broaden the bandwidth.

The simulated S11 of antenna with three slots is shown in Fig. 3. With slot height of $h_{s}=1.1,1.3,1.5$ and 1.7, the simulated S11 is shown in Fig. 3(a). As $h_{s}$ increases, the lower resonant frequency at around $3 \mathrm{GHz}$ shifts down a little bit, but with the lower cutoff frequency $(\mathrm{S} 11=-10 \mathrm{~dB})$ remaining unchanged. However, the higher frequency resonance at around $15 \mathrm{GHz}$ moves down significantly with stronger magnitude, reducing S11 at higher frequencies and hence increasing the impedance bandwidth toward the high frequency. The resonance at around $8 \mathrm{GHz}$ is weaker with increased $h_{s}$, which increases $\mathrm{S} 11$ at round $5.5 \mathrm{GHz}$. Thus a compromise must be made to obtain a good performance of $\mathrm{S} 11$ for the whole frequency band. In our design, the optimum $h_{s}$ is equal to the gap between the radiator and the ground plane, which is $1.5 \mathrm{~mm}$.

The results of parametric study on $l 4$ and $l 3$, which determine the positions of slots $3 \& 2$ on the ground plane, are shown in Figs. 3(b) and 3(c), respectively. Fig. 3(b) shows that when $l 4$ decreases from 13.3 to $12.1 \mathrm{~mm}$, the middle resonant frequency shifts very slightly from 8 to 7.7 $\mathrm{GHz}$, while the higher resonant frequency also shifts down slightly from 16 to $15.7 \mathrm{GHz}$. When $l 4$ set at a fixed value of $12.9 \mathrm{~mm}, 13$ determines the position of slot 2. Fig. 3(c) shows that when $l 3$ increases from 2.8 to $3.4 \mathrm{~mm}$, the middle resonant frequency shifts down slightly from 8 to 7.6 $\mathrm{GHz}$, while the higher resonant frequency shifts up significantly from 15.9 to $16.8 \mathrm{GHz}$. It can be seen that $l 4$ and $l 3$ affect the middle resonant frequency at around $8 \mathrm{GHz}$ and higher resonant frequency at $16 \mathrm{GHz}$. However, they do not affect the lower resonant frequency at about $3.5 \mathrm{GHz}$. The position of slot 1 is determined by $l 1$. The simulation S11 with different values of $l 1$ is shown in Fig. 3(d). As $l 1$ decreases from 6.8 to $6.5 \mathrm{~mm}$, the different resonant frequencies do not shift much. However, the resonances below 8 $\mathrm{GHz}$ are only slightly affected but the resonances above 8 $\mathrm{GHz}$, i.e. at around 11 and $14 \mathrm{GHz}$, are significantly weaker which reduces S11. Since if $l 3$ and $l 4$ are fixed, the value of $l 2$ will change with $l 1$ which also determines the position of slot 1 , thus the parametric study on $l 2$ is not necessary.

\subsection{Simulated current distribution}

The operation of the proposed antenna is further studied using current distributions at different resonant frequencies. At $3 \mathrm{GHz}$, the simulated results in Fig 4(a) shows that the current is mainly on the bottom edge of the radiator close to slots 2 and 3 which contributes to the resonance. At $8 \mathrm{GHz}$, Fig. 4(b) shows that the current is mainly at the left edge of the radiator and on slot 1 . While at $14 \mathrm{GHz}$, Fig 4(c) shows that the current is mainly on slots 1 and 2. Higher mode operation can also be seen at the left edge of the radiator. Very little current is on slot 3.

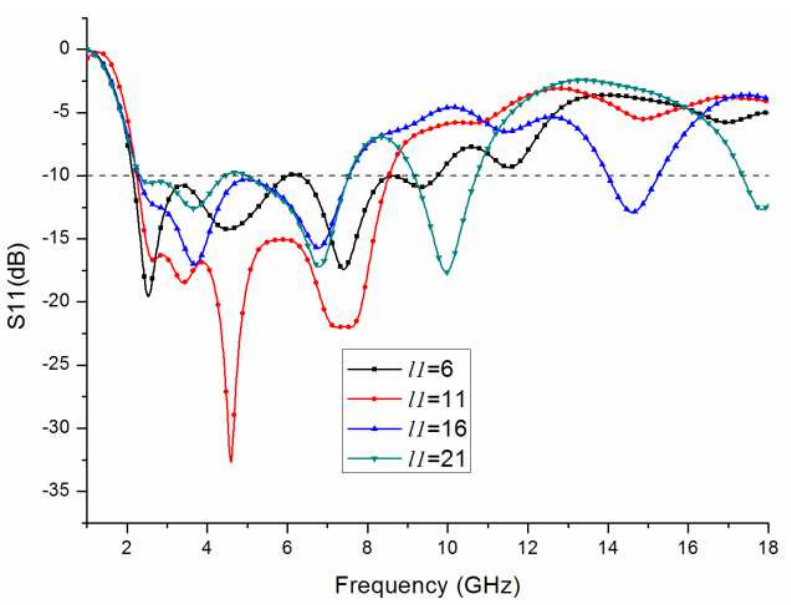

(a)

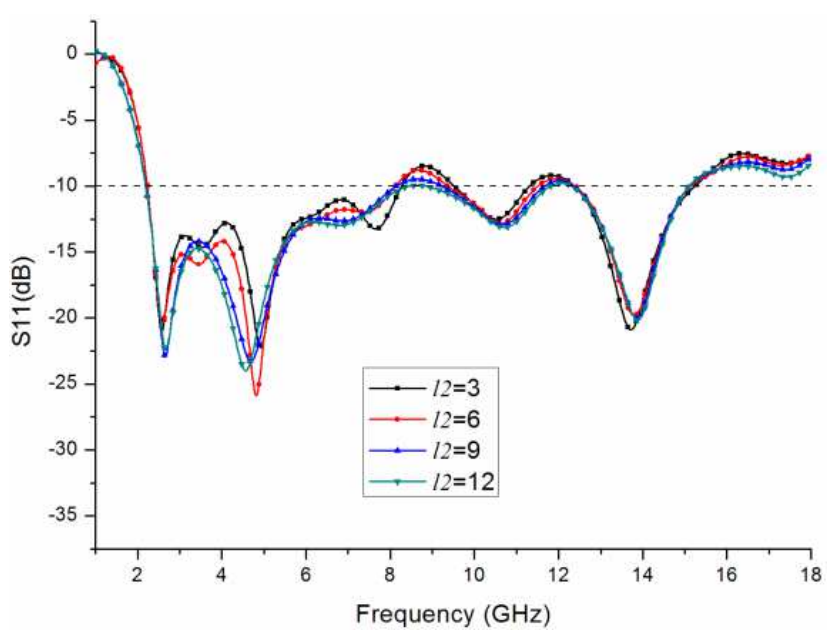

(b)

Figure 2. Simulated S11 with (a) one slot, and (b) two slots with $11=6 \mathrm{~mm}$

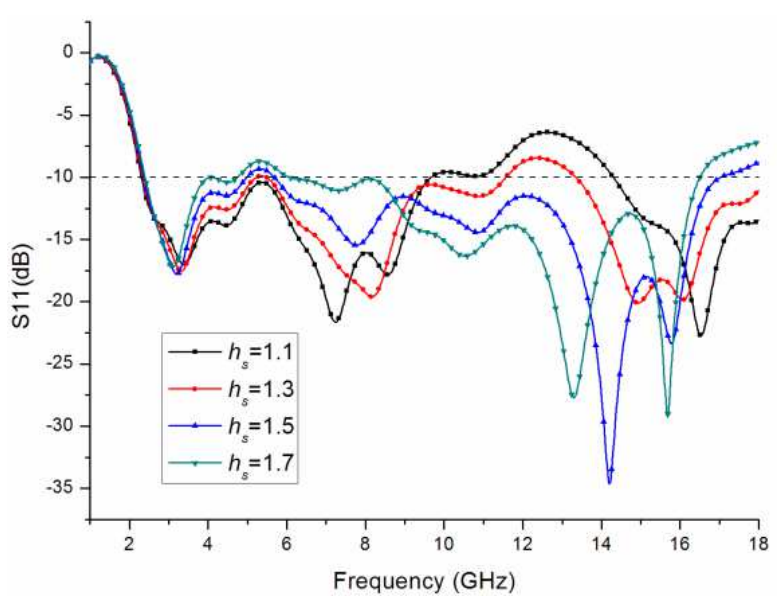

(a) 


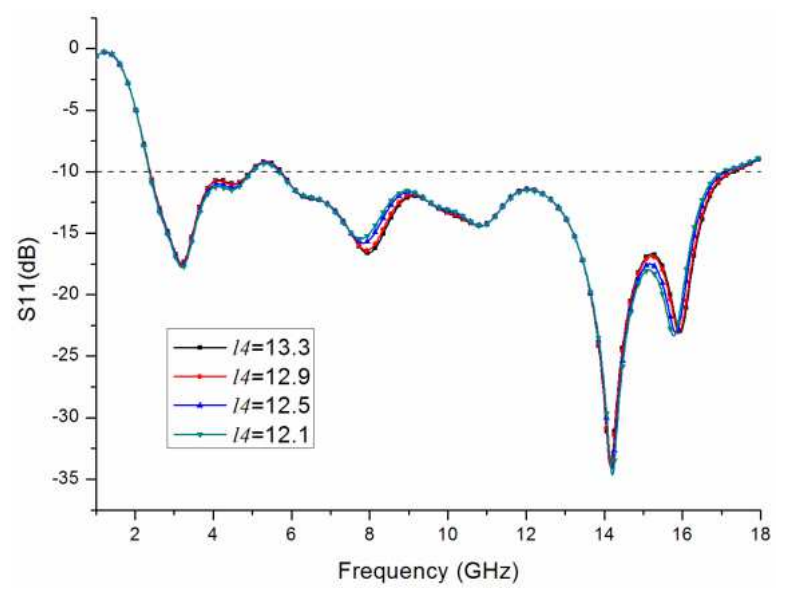

(b)

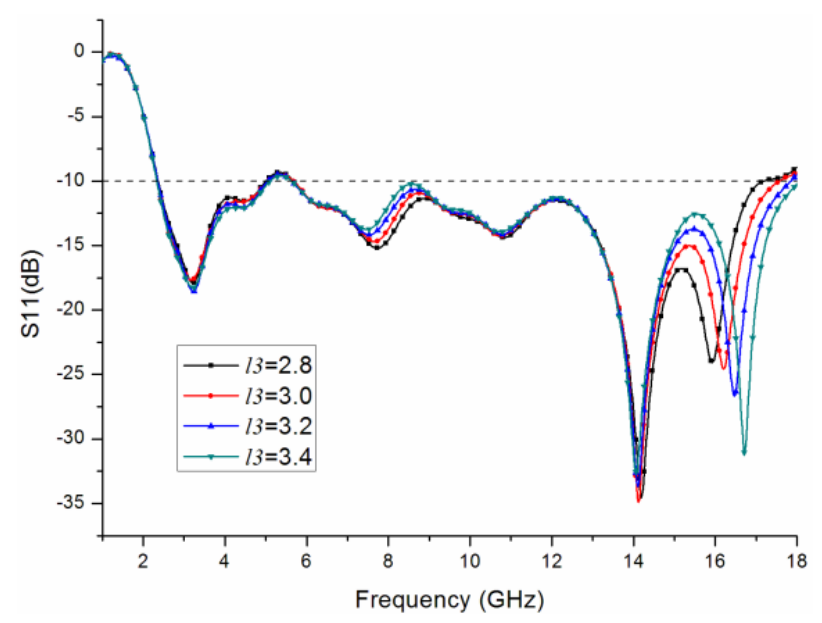

(c)

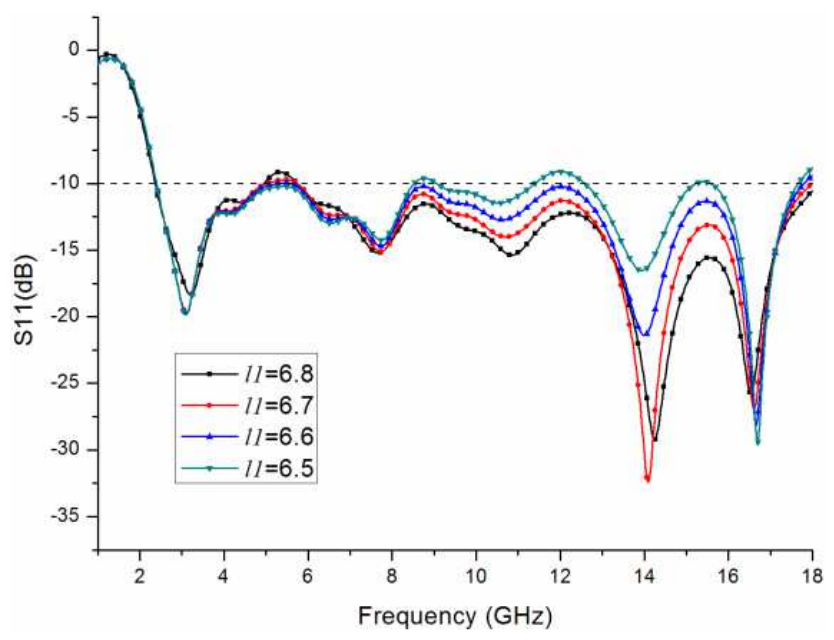

(d)

Figure 3. Simulated S11 with (a) one slot, and (b) two slots with $l 1=6 \mathrm{~mm}$

\section{Results and Discussions}

The proposed antenna shown in Fig. 1(a) has been studied and designed using computer simulation. For verification of simulation results, the antenna has also been fabricated as shown in Fig. 1(c) and measured using the Satimo Starlab System.

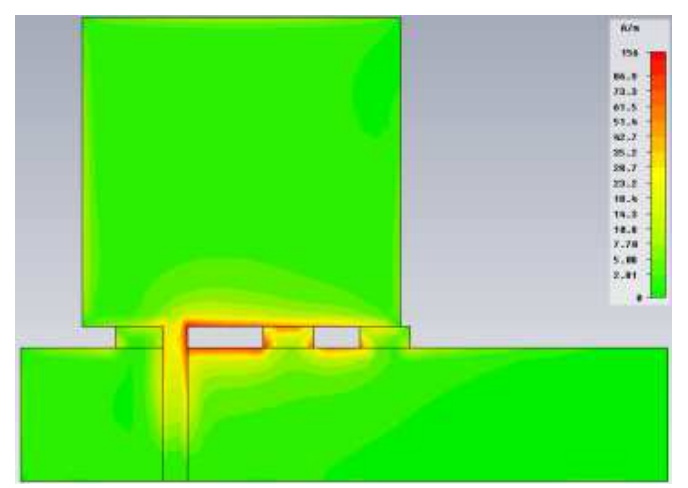

(a)

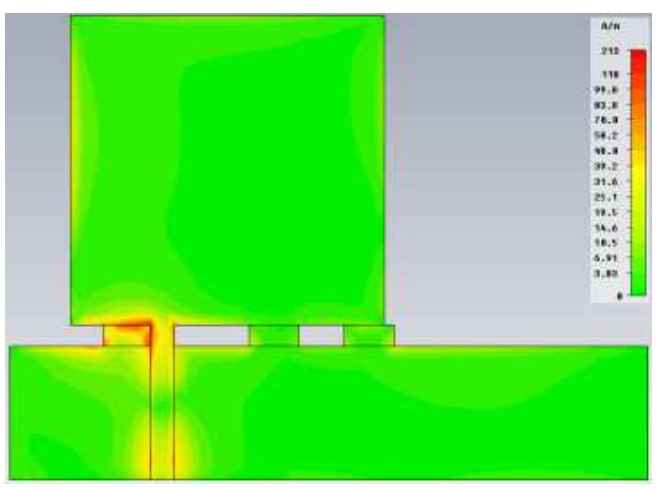

(b)

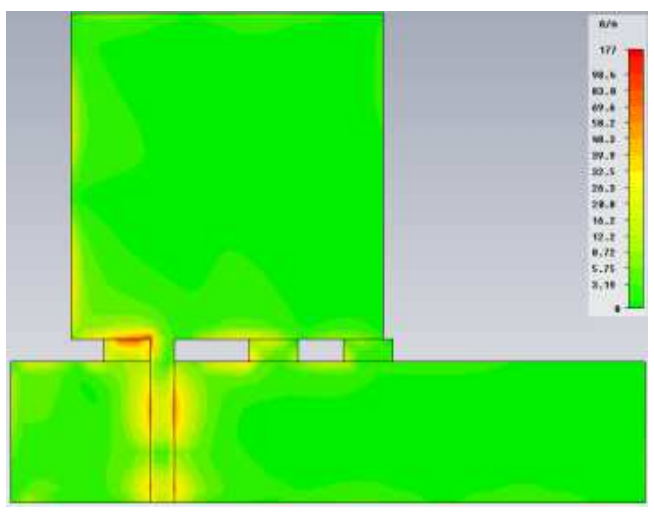

(c)

Figure 4. Simulated current distribution at (a) $3 \mathrm{GHz}$, (b) $8 \mathrm{GHz}$ and (c) 14 $\mathrm{GHz}$

The simulated and measured S11 of the antenna are shown in Fig. 5. The antenna has a measured impedance bandwidth from 2.38 to $14.5 \mathrm{GHz}$. Results of more studies have showed that the small discrepancy between the simulated and measured results below about $14 \mathrm{GHz}$ is mainly due to the soldering, fabrication tolerance, measurement tolerance and SMA connector, while the large discrepancy above about $14 \mathrm{GHz}$ is mainly due to the SMA connector and measurement tolerance. The peak gain and efficiency of the antenna are shown in Fig. 6. Simulated and measured results showed good agreements. The antenna has a maximum measured gain of $5.9 \mathrm{dBi}$ at $12.7 \mathrm{GHz}$ with an average 
gain of $4.42 \mathrm{dBi}$ from 2.38 to $14.5 \mathrm{GHz}$. It has a maximum measured efficiency of $95.3 \%$ at $3 \mathrm{GHz}$ with an average of $86.6 \%$ through the whole bandwidth from 2.38 to $14.5 \mathrm{GHz}$. The efficiencies in simulation and measurement do not agree well at high frequencies from about 15 to $16 \mathrm{GHz}$, which is mainly due to the SMA connector and measurement tolerance. The radiation patterns of the antenna at 2.45, 10 and 14 $\mathrm{GHz}$ are shown in Fig. 7. It can be seen that the antenna does not have dumb-bell shaped radiation patterns in the yz-plane (the E-plane) like a normal monopole should have. At all these three frequencies, the radiation patterns in the yz-plane do not have obvious nulls on top and bottom of the antenna. More simulated results have showed that, without the slots on the ground plane and/or without offset-fed, the antenna behaves like a normal monopole, having dumb-bell shaped radiation patterns in the yz-plane. This indicates that it is the offset feed line and slots on the ground plane which cause the radiation pattern in the yz-plane to be more omnidirectional, making the antenna more suitable for on-body communications. Since the antenna can be put in parallel with the body surface, it has low profile.

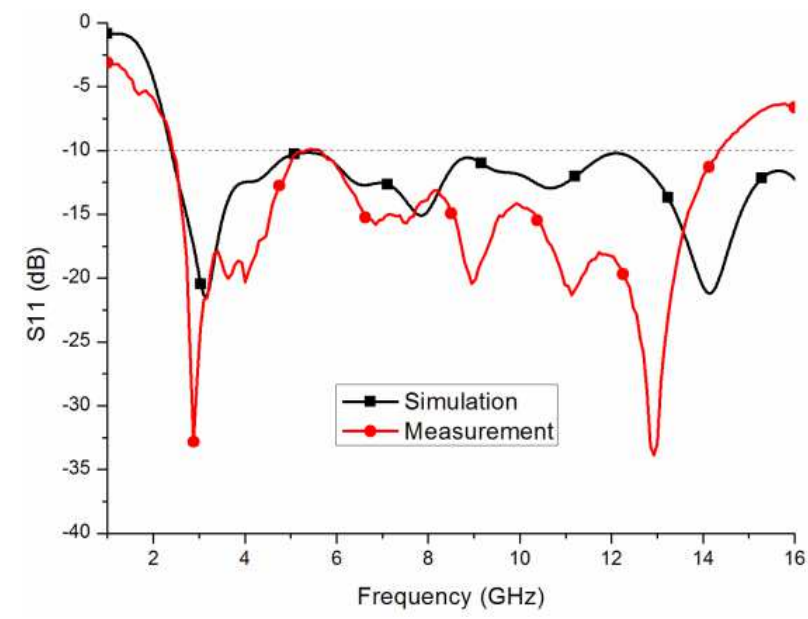

Figure 5. Simulated and measured S11 of the antenna

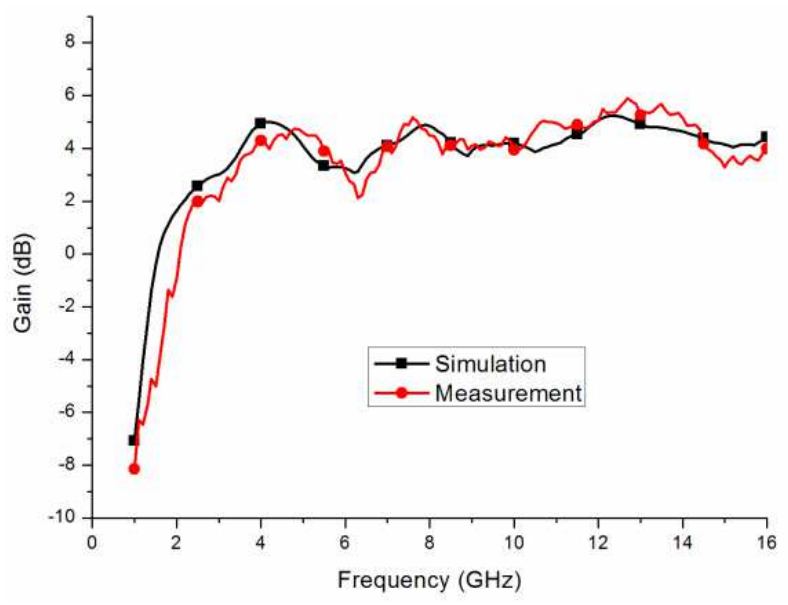

(a)

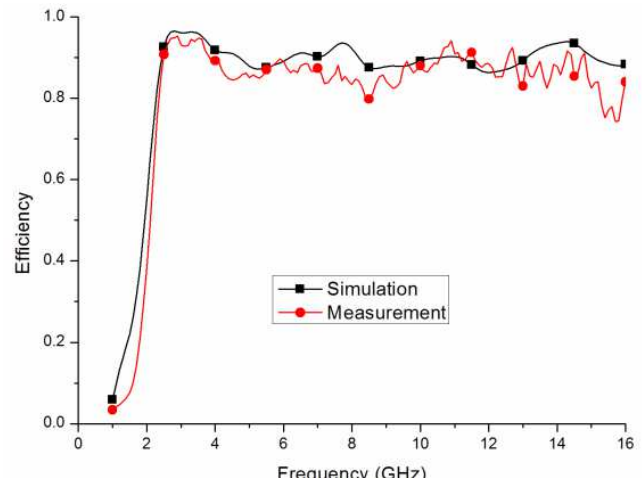

(b)

Figure 6. Simulated and measured (a) peak gains and (b) efficiencies

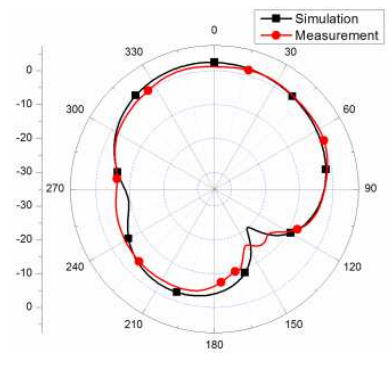

(a) $2.45 \mathrm{GHz}$

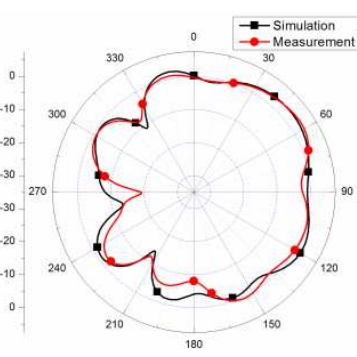

(c) $9 \mathrm{GHz}$

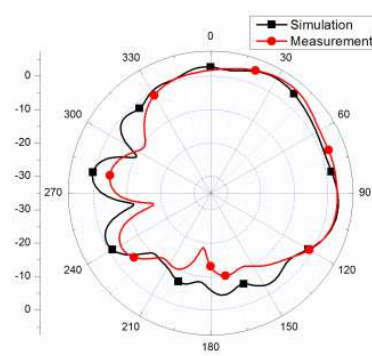

(e) $13 \mathrm{GHz}$

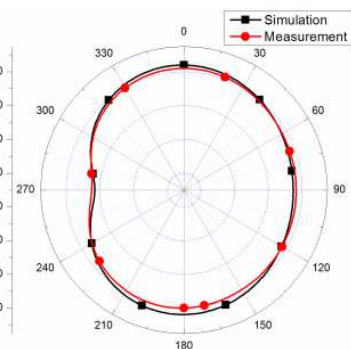

(b) $2.45 \mathrm{GHz}$

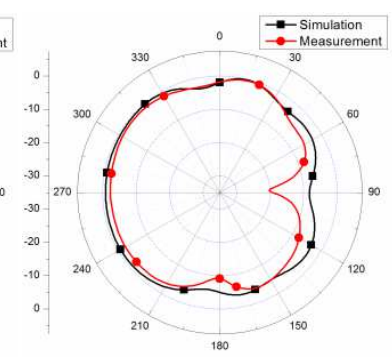

(d) 9 GHz

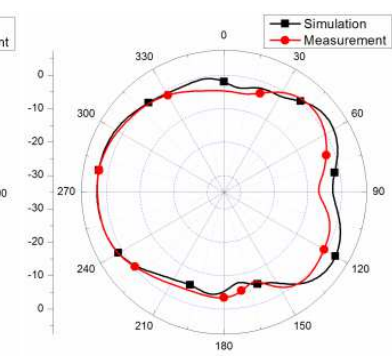

(f) $13 \mathrm{GHz}$

Figure 7. Simulated and measured radiation patterns at (a) $2.45 \mathrm{GHz}$, (c) $10 \mathrm{GHz} \&$ (e) $14 \mathrm{GHz}$ in y-z plane and (b) $2.45 \mathrm{GHz}$, (d) $10 \mathrm{GHz} \&$ (f) 14 GHz in $x$-y plane

\section{Conclusions}

An ISM/UWB monopole antenna with offset-fed and a slotted ground plane has been designed and proposed for on-body communications. The antenna has a size of $40 \times 33$ $\mathrm{mm}^{2}$. An offset feed line and three rectangular slots used at the top edge of the ground plane are used to improve im- 
pedance matching, creating a wide bandwidth from 2.38 to 14.5 GHz for the antenna. More importantly, they are also used to improve the radiation characteristic in the E-plane for on-body communications, making the antenna suitable for body-centric communications.

\section{References}

[1] Federal Communications Commission, Revision of Part 15 of the Commission's Rules Regarding Ultra-Wideband Transmission System from 3.1 to $10.6 \mathrm{GHz}$, in Federal Communications Commission, Washington, DC: ET-Docket, pp: 98-153, 2002.

[2] R. A. Scholtz, "The Spread Spectrum Concept," IEEE Trans. on Communications, vol. 25, issue 8, pp. 748-755, 1977

[3] Y. T. Lo, D. Solomon and W. Richards, "Theory and experiment on microstrip antennas," IEEE Trans. on Antennas \& Propg., vol. 27, issue 2, pp. 137-145, 1979

[4] T. M. Weller, L. P. B. Katehi and G. M. Rebeiz, "High performance microshield line components," IEEE Trans. on Microwave Theory and Techniques, vol. 43, issue 3, pp. 534-543, 1995

[5] P. Salzenstein, O. Dupuis and D. Lippens et al, "Coplanar waveguides on dielectric menbranes micromachined on a GaAs substrate," Electronics Letters, vol. 32, issue 9, pp. 821-822, 1996

[6] D.B. Lin, I. T. Tang, and M. Y. Tsou, "A compact UWB antenna with CPW-fed," Microw. Opt. Technol. Lett., vol. 49, pp. 372-375, 2007.

[7] Y. J. Ren and K. Chang, "Ultra-wideband planar elliptical ring antenna," Electron. Lett., vol. 42, no. 8, pp. 447- 449, 2006.

[8] J. Liang, C. C. Chiau, X. Chen, and C. G. Parini, "Printed circular ring monopole antennas," Microw. Opt. Technol. Lett., vol. 45, pp. 372-375, 2005.

[9] K. Kiminami, A. Hirata, and T. Shiozawa, "Double-sided printed bow-tie antenna for UWB communications," IEEE Antennas Wireless Propag. Lett., vol. 3, no. 1, pp. 152-153, 2004.

[10] Y. Y. Sun, S. W. Cheung and T.I. Yuk, "Studies of Planar Antennas with Different Radiator Shapes for Ultra-wideband Body-centric Wireless Communications," Progress In Electromagnetics Research Symposium (PIERS) 2011. Suzhou, China, 12-16 September, 2011

[11] L. Liu, S. W. Cheung and T. I. Yuk, "Bandwidth Improvements Using Ground Slots for Compact UWB Microstrip-fed Antennas," Progress In Electromagnetics Research Symposium (PIERS) 2011. Suzhou, China, 12-16 September, 2011

[12] M. M. Matin, B.S. Sharif, and C.C. Tsimenidis, "Probe fed stacked patch antenna for wideband applications," IEEE Trans. Antennas Propag., vol. 55, no. 8. pp. 2385-2388, 2007.

[13] R. J.-M. Cramer, R. A. Scholtz and M. Z. Win, "Evaluation of an ultra-wide-band propagation channel," IEEE Trans. on Antennas \& Propg., vol. 50, issue 5, pp. 561-570, 2002
[14] S.H. Wi, Y. B. Sun, I. S. Song, et al., "Package-Level integrated antennas based on LTCC technology," IEEE Trans. Antennas Propag., vol. 54, no. 8, pp. 2190-2197, 2006.

[15] K. Ray and Y. Ranga, "Ultrawideband printed elliptical monopole antennas," IEEE Trans. Antennas Propag., vol. 55, no. 4, pp. 1189-1192, 2007.

[16] K. Kim and S. Park, "Analysis of the small band-rejected antenna with the parasitic strip for UWB," IEEE Trans. Antennas Propag., vol. 54, no. 6, pp. 1688-1692, 2006.

[17] J. Choi, K. Chung, and Y. Roh, "Parametric analysis of a band-rejected antenna for UWB applications," Microw. Opt. Technol. Lett., vol. 47, pp. 287-290, 2005.

[18] H. Zhao, J. G. Liang and F. S. Zhang et al., "Design of a Compact Dual Band Antenna for Bluetooth and UWB Applications," International Symposium on Antennas, Propagation \& EM Theory (ISAPE) 2012. Xi' an, China, 22-26 Oct, 2012

[19] S. K. Mishra, R. K. Gupta, and J. Mukherjee et al, "A Compact Dual-Band Fork-Shaped Monopole Antenna for Bluetooth and UWB Applications," IEEE Antennas Wireless. Propag. Lett., vol. 10, pp.627-630, 2011

[20] M. J. "A Dual-Band Planar Monopole Antenna for $2.4 \mathrm{GHz}$ ISM and UWB Applications," IEEE $27^{\text {th }}$ convention of Electrical \& Electronics Engineers in Israel (IEEEI) 2012. Eilat, Israel, 14-17 Oct, 2012

[21] S. Tu, Y. C. Jiao and S. M. Ning et al, "Small Internal 2.4-GHz/UWB Antenna for Wireless Dongle Applications," IEEE Antennas Wireless. Propag. Lett., vol. 9, pp.284-287, 2010

[22] Z. N. Chen, D. X. Liu and B. Gaucher, "A Planar Dualband Antenna for $2.4 \mathrm{GHz}$ and UWB Laptop Applications," IEEE $63^{\text {rd }}$ Vehicular Technology Conference 2006. Melbourne, Vic., Australia, 7-10 May, 2006

[23] P. S. Hall and Y. Hao, Eds., Antennas and Propagation for Body-Centric Wireless Communications. Norwood, MA: Artech House, 2006.

[24] A. Alomainy, Y. Hao and P. S. Hall, et al, "Comparison between two different antennas for UWB on-body propagation measurements," IEEE Antennas Wireless. Propag. Lett., vol. 4, pp.31-34, 2005

[25] A. Alomainy, A. Sani and Y. Hao, et al, "Transient characteristics of wearable antennas and radio propagation channels for ultrawideband body-centric wireless communications," IEEE Trans. Antennas and Propag., vol. 57, no. 4, pp. 875-883, 2009.

[26] X. N. Low, Z. N. Chen, and T. S. P. See, "A UWB dipole antenna with enhanced impedance and gain performance," IEEE Trans. Antennas Propag., vol. 57, no. 10, pp. 2959-2966, 2009.

[27] Z. N. Chen, A. Cai, T. S. P. See, and M. Y. W. Chia, "Small planar UWB antennas in proximity of the human head," IEEE Trans. Microw. Theory Tech., vol. 54, no. 4, pp. 1846-1857, 2006. 